\title{
A PRÁTICA ESPORTIVA E ATIVIDADE FÍSICA PODEM EDUCAR PESSOAS ATRÁS DAS
} GRADES?

Marco Ferretti

Jorge Dorfman Knijnik

\section{Resumo}

O esporte e a atividade física são vistos formas de criar uma pessoa saudável nos aspectos físicos e psicológicos, através da educação de valores considerados positivos pela sociedade. Sendo o esporte e atividade física fossem capazes disso, supondo-se que ambos poderiam ser ferramentas da Educação Física (EF) para recuperar presos e auxiliarem a reinserção na sociedade. Este trabalho entrevistou 3 exdetentos através de um grupo focal para identificar a possibilidade de se educar pela EF e o ambiente em que a EF pode ser introduzida. Porém o esporte e a atividade física são apenas ferramentas e para se obter os resultados desejados devem ser bem manuseadas, mas devido a forma como o sistema prisional esta organizado a EF ficaria emperrada na tentativa de atingir os seus objetivos e a prática esportiva que ocorre atrás das grades reflete o ambiente que o cerca.

\section{Palavras-chave}

Sistema carcerário; Detento; Educação física; Direitos humanos

\begin{abstract}
The sports and physical activities can make the people healthier in physical and psychological aspects and can teach the "social values goods". If the sport and physical activities can does this and both are parts from Physical Education (PE), can they recover the prisoners and help yours return to the society? This paper interviewed 3 ex-prisoner with focus-group technique to see if is possible teach using the PE and to identify the local where will can be introduced the PE. But sports and physical activities are only tools and only on good hands will produce good thing, the prison system don't have support to PE like educative, the PE on prison have same surround values.
\end{abstract}

\section{Key-words}

Prison system; Prisoner; Physical Education; Human rights 


\section{INTRODUÇÃO}

No inicio do século XIX o condenado tinha o corpo como alvo da repressão penal que era feito na forma de espetáculo e com sensações insuportáveis de dor como forma de castigo para o condenado (FOUCAULT, 1984).

Com a finalidade de tornar "mais humanas" as punições durante a idade média, os transgressores passaram a ser confinados na masmorra e depois na prisão (FOUCAULT, 1984).

Na prisão passou-se a iluminar e expor o preso para ser mais vigiado, seguindo a teoria do panótico. Sentir-se sempre olhado faz o preso ter consciência da sua visibilidade e a permanência da ordem do poder (FOUCAULT, 1984).

A ONU e os Direitos Humanos têm a visão de que além de vigiar e punir as penitenciárias devem reintegrar os presos a sociedade. A Educação Física poderia ser uma ferramenta para a incorporação de valores aceitos pela sociedade e facilitar o retorno para a liberdade.

A ressocialização deve ser um projeto com finalidade re-educadora para reintegrar indivíduos que romperam as regras sociais e foram julgados e punidos (DE CARVALHO, 2004).

A "ressocialização" tupiniquim não valoriza o local onde os presos passarão por um período da sua vida, deixando o local descuidado e degradante (VASCONCELOS, 2000), carcereiros preferem impor a ordem e o respeito através da violência (GÓES; MAKINO, 2002 e VASCONCELOS, 2000) e a direção ignora a utilização exagerada da força por parte dos carcereiros (VASCONCELOS, 2000) e a população apóia pensando ser a melhor forma de diminuir a criminalidade ao invés de valorizar ações sociais (SEQUEIRA, 2004).

Se há um interesse de mudar o crescimento da violência, ela não ocorrerá com o aumento do caráter punitivo e isolando da população que está a margem da sociedade. A prática esportiva pode ser um meio para auxiliar os detentos a absorverem valores considerados positivos pela sociedade se estivermos pensando nas penitenciárias como forma dos presos serem reintegrados a sociedade e não isolá-los da mesma, pois dessa forma o sistema prisional vem apresentando resultados opostos a reinserção do exdetento a sociedade de forma pacífica. 
O QUE ACONTECE LÁ DENTRO?

Os presos passam o dia em um ócio que é causado pela falta de oportunidades de trabalho e de atividades educativas, além de sofrerem com a ociosidade, eles suportam conflitos entre eles próprios ou com os guardas e isso aumenta a tensão de viver (VASCONCELOS, 2000), ou porque não "de sobreviver", neste local.

O Estado brasileiro não investe nas prisões para reintegrar os presos, investe apenas para aumentar a sua capacidade, assim há falta de vagas para as atividades de trabalho e educação, como também não existem grupos que auxiliem os consumidores de drogas (DE CARVALHO, 2004).

Uma forma de reeducar os presos seria através da pedagogia da autonomia na Educação Física, a pedagogia da autonomia preocupa-se em desenvolver um aluno capaz de pensar a busca da solução de um problema através da cooperação, que trabalhem visando a evolução de todos. Pensa em uma prática esportiva que deixaria de ser a superação do mais fraco para ser a auto-superação e um ajudaria na dificuldade do outro (KORSAKAS; DE ROSE JR, 2002).

\section{ADQUIRINDO VALORES NA EDUCAÇÃO FÍSICA}

Sob a perspectiva pedagógica a EF possibilita organizar/centralizar o corpo, contribuir para o movimentar-se/relacionar-se humano na e para a educação do homem e desse modo o aluno absorve valores que tenha modos mais adequados ao se deparar com situações do cotidiano, ser capaz de autoorganizar, interferir no seu meio e de ser ético (PASTRE, 2001).

Há um predomínio de práticas esportivas nas aulas de EF, nos valores do esporte na Grécia Antiga, a dignidade estava no espírito guerreiro e competitivo e não no resultado. Os gregos dividiam a virtude, o areté, em física e espiritual do atleta; a física esta relacionado com a saúde, vigor, beleza, força e destreza e a espiritual com sagacidade, bondade, prudência, justiça, amor a arte e astúcia (RUBIO; CARVALHO, 2005).

No início dos jogos esportivos na Inglaterra o areté seria o fair play dos ingleses. Com o fair play o atleta comporta-se de forma ética e moral e se utilizará apenas dos próprios meios para competir (RUBIO; CARVALHO, 2005). 
$\overline{\mathrm{O} \text { fair play foi absorvido pelo barão de Coubertin na recriação dos jogos olímpicos, pois não interessava a }}$ vitória a qualquer custo e procurava-se a honestidade, lealdade, o respeito com o oponente, colaboradores, árbitros e a si próprio, mas esses valores foram postos a prova com o fim do amadorismo nas olimpíadas e início do profissionalismo (RUBIO; CARVALHO, 2005).

Porém a EF e projetos esportivos bem delineados conseguem esquivar dos vícios existentes no esporte profissional. Nos EUA existem diversos programas de educação esportiva para adolescentes e alguns deles para a prevenção do crime. Essa expansão se deve por ser de fácil e de baixo custo para implementação e por conseguir donativos devido a credibilidade social que o esporte tem em levar pessoas para o bom caminho (HARTMANN; DEPRO, 2006).

Foram analisados os dados criminalísticos de 1985 a 2001, ao compararem as taxas de criminalidade das cidades estadunidenses que foram implantadas o Projeto Basquete à Meia Noite com as cidades sem o projeto foi encontrado que as cidades com o projeto tiveram uma maior redução na criminalidade, isso ocorreu porque o Projeto Basquete à Meia Noite foi implantado juntamente com outras medidas de segurança, a divulgação positiva da mídia pode ter intimidado os criminosos ao mostrar que há medidas de segurança, como também dando uma nova perspectiva aquela comunidade e isso fez com que se reduzisse comportamentos individualistas e anti-sociais (HARTMANN; DEPRO, 2006).

Uma pesquisa sobre a atividade física e comportamento anti-social, identificou na analise de 175 programas o oferecimento de várias modalidades esportivas, atividades físicas e atividades ao ar-livre (ex.: escoteiro e acampamento) para jovens, o foco na maioria dos programas é a habilidade social e autoestima, é mais importante a forma como é realizada a tarefa para o jovem do que o quê se está praticando, o envolvimento da comunidade é importante para o sucesso do programa, atividades em grupo são utilizadas para o desenvolvimento social. Esses achados indicam que a prática esportiva e a atividade física reduzem o tédio e pode ser usado contra a baixa auto-estima e baixa autoconfiança, aumenta as habilidades sociais como a relação interpessoal, a comunicação e reduz o comportamento anti-social (MORRIS; SALLYBANKS; WILLIS; MAKKAI, 2003).

\section{MATERIAIS E MÉTODOS}

Foi realizado um grupo focal com 3 ex-detentos, essa técnica de pesquisa tem a vantagem de se evitar mentiras ou exageros, mas tem a desvantagem de disputa de poder entre as pessoas e inibição de falar em público (THOMAS; NELSON, 2002), porém nessa pesquisa esses problemas foram amenizados pelo fato 
$\overline{\text { do grupo ser pequeno e das } 4 \text { pessoas se conhecerem antes da realização da entrevista, sendo que os }}$ entrevistados moravam próximos uns dos outros.

A entrevista seguiu a linha de guiada, a entrevista guiada pode ser organizada com temas separados a serem abordados, pode organizar a entrevista colocando possíveis perguntas a serem realizadas em cada tema e levantar tópicos que podem ser abordados em cada pergunta (RICHARDSON, 1989).

Antes de iniciar as perguntas os participantes foram avisados sobre o objetivo da pesquisa, que não eram obrigados a participar, que poderiam responder apenas o que lhes conviessem responder e que o anonimato seria garantido, dessa forma todos concordaram em participar.

Através das perguntas buscou-se identificar nos ex-detentos, se participaram de algum projeto social que envolvesse prática corporal, identificar como está organizado o sistema prisional e como é o retorno para a sociedade, através desses dados identificar se a EF interferiu na vida dessas pessoas antes ou durante o tempo em que estiveram presas e as possibilidades da implantação da EF nos locais de detenção para auxiliar no reingresso a sociedade.

A forma de transcrição foi através transcrição literal em que se transcreve exatamente o que é falado. A pergunta sobre histórias que eles recordavam foi deixada por último para que lembranças que surgissem após a entrevista fossem relatadas e logo que possível foram registradas de forma resumida. As respostas foram avaliadas através da literatura para chegar às conclusões.

\section{RESULTADO E DISCUSSÃO}

EF DA ESCOLA

De acordo com "Y" "na escola tinha explicação do professor sobre regras, mas era mais atividade mesmo, mais prático, ele dava a bola e a gente jogava bola", "X"relatou que nas aulas de EF "era futebol e as vezes vôlei e [o professor] orientava para praticar bastante esporte", "Z" fazia "futebol e voleibol, exercício físico também... exercitar primeiro, [o professor] dava instrução e pau no [e fazíamos] futebol”.

O trabalho do professor de EF deveria ir além de um simples ato de ensinar as regras do jogo, dar aquecimento e depois fazer o papel de arbitro, a EF

[...] mais do que ensinar a fazer, o objetivo é que os alunos e alunas obtenham uma contextualização das informações como também aprendam a se relacionar com os colegas, reconhecendo quais valores estão por trás de tais práticas (DARIDO; RANGEL-BETTI; RAMOS; GALVÃO; FERREIRA; MOTA; SILVA; RODRIGUES; PONTES; CUNHA, 2001, p. 4-5). 


\section{ATIVIDADES DE PRESO}

O cotidiano do detento resumido por " $X$ " começava quando "abria a tranca [cela] as 7 da manhã e a gente saia, alguns iam pra escola, uns iam pro serviço, outros ficavam lá mesmo no pátio, no pátio ficava sem fazer nada".

As escolas nos locais de reclusão não atingem os seus resultados, pois costuma ter faltas de alunos para atendimento jurídicos, médico ou social, por causa do trabalho, por ter a opção de não ir à aula em certos dias e em dias com atividades, principalmente as de modalidades esportivas, onde os presos realizam apostas nos campeonatos (PORTUGUES, 2001).

Quanto ao trabalho, realizado apenas por "X", a sociedade vê a atuação do trabalho sobre o preso como forma de reeducá-lo, mas esse pensamento de que a maldade pode sair pela transpiração ocorrida durante o trabalho é ingênuo (MAIA, 2003).

Ao premiar o detento trabalhador gera nele a sensação de que o trabalho realmente compensa (PEREIRA, 2000), porém quando tem remuneração, ela é baixa, o que retira sua função formativa e educadora tornando-se um castigo ou trabalho escravo (MACIAL, 2003) e fora da detenção o baixo rendimento resulta em demissão enquanto que o preso é avaliado pelo seu comportamento no trabalho (MAIA, 2003). "Y" fala que "tinha manuais, cada um tinha um tipo de serviço, tipo trabalho artesanal" e "X" relatou que "fazia maquete, esquadros, tapete e abajur". Enquanto que a maioria dos trabalhos atuais dos grandes centros metropolitanos é de serviços, nos presídios ainda realiza-se trabalho artesanal, o que caracteriza uma desarmonia entre o trabalho intramuros e extramuros.

\section{O LOCAL}

O ambiente em que ficaram detidos estava mal conservado e pouco higiênico, conforme "Y" "lá é mal acabado mesmo, [...] mas a limpeza lá é só os próprios presos que fazem [...], mas lá freqüentava muito rato, barata também e o material [de limpeza] [...] é só com água, vassoura e "rodão"”.

As luzes eram apagadas deixando o local escuro e o mesmo acontecia com a água como foi relatado por "Y” que "pra economizar a luz eles cortavam a luz, a água também [...] e a luz só entrava pela porta da cela, então imagina uma cozinha, a porta só ilumina a entrada”. 
Sobre o local que esteve "X", ele relatou que "tinha umas bolas no meio pra você não ficar muito tempo deitado, é pras costas doer". Esse ambiente afeta negativamente o preso e piorando a sua recuperação. A arquitetura cria uma situação de simbiose com o sujeito, devido ao descaso do local, a rudeza, austeridade, deterioração e por ser primitivo, dificilmente o preso vislumbrará emoções positivas e construtivas (DE SÁ, 2003).

\section{SAÚDE}

A preocupação com a saúde é quase inexistente. " $X$ " relatou que quanto mais tempo preso, maiores são os problemas com os dentes, colegas pegaram AIDS na cadeia e "X" e "Y" relataram que a comida não é preparada de forma adequada. Policiais não queriam levar "Y" quando estava com hérnia inguinal para o hospital e quando foi o médico não fez um bom trabalho.

A saúde pública não esta boa, pior ainda encontra-se a saúde dentro dos presídios e cadeias. Ao ser examinadas 225 presas de 18 a 61 anos do Centro de Ressocialização Feminino de Rio Claro - SP, foram encontrados valores superiores de doenças como AIDS e hepatite $\mathrm{C}$ ao da população brasileira (BERRA; BACETTI; BUZO, 2006).

Não é somente a saúde física que necessita de atenção, psicologicamente o preso é afetado, isso ocorre com a perda da identidade, sentimento de inferioridade, estreitamento do horizonte psíquico, pobreza de experiência, dificuldade em elaborar planos de médio e longo prazo, infantilização e regressão (DA FONSECA, 2006).

Com relação a ajuda psicológica "Z" relatou que "em D.P. mesmo quem vai dar um conforto é o pessoal da igreja, [..] mas acompanhamento do psicólogo, da medicina não tem não", mas por onde "Y" e " $X$ " passaram teve pastor, psicólogos e assistentes sociais auxiliando os presos.

A coordenação de atividade física seria uma forma de proporcionar saúde aos detentos, porém no estado em que se encontram os cuidados com a saúde dentro dos presídios é de se questionar como seriam tratadas as lesões que ocorressem durante a prática esportiva.

\section{FUNCIONÁRIOS DE SEGURANÇA}

"X" e "Y" relataram agressão sofrida pelos carcereiros e os 3 pela polícia. Nas palavras de "Y" "fui muito agredido pelos policiais" e "X" concordou relatando que foi torturado por toda a noite para delatar 
o companheiro de crime. Isso demonstra que carcereiros e policiais não tem o preparo adequado para buscar a reinserção do detento e a punição torna-se o foco deles.

A justificativa dos carcereiros para usar a violência é de que ao serem desrespeitados e não responderem violentamente, os outros detentos farão a mesma coisa e o carcereiro começará a correr risco de vida (VASCONCELOS, 2000).

$\mathrm{O}$ agente penitenciário vai seguir a filosofia da administração que na maioria das vezes permite a utilização da violência física, mas o agente também pode "dá parte" (fazer queixa formal) e o preso é punido de outras formas (VASCONCELOS, 2000).

Os funcionários responsáveis pelos presos não estão preparados para tal função, eles entendem que o preso está lá para ser castigado diariamente o que explicaria o aumento da periculosidade do preso ao invés da ressocialização (GOMES, 2006).

A entrada de pessoas, realmente preocupadas com a reintegração dos presos, nas penitenciárias e cadeias pode auxiliar a reinserção do preso e inibir comportamentos indevidos por esses funcionários.

Os presos são "nossos detentos", porque estão nessa condição por contribuição da sociedade e o descaso das autoridades com eles (PINHEIRO, 1998).

Um caminho para a entrada da sociedade civil nos presídios é através das ONGs, a parceria entre ONGs e a Secretaria da Administração Penitenciária do Governo do Estado de São Paulo fez com que reduzissem os custos, a reincidência e a fuga prisional (DA FONSECA, 2006).

Além de ONG, é importante as universidades encaminhem estagiários no trabalho voluntariado ou agências forneçam bolsas de estudo para alunos que queiram trabalhar com os presos (DA FONSECA, 2006).

Outra forma da sociedade ter outro olhar para dentro dos muros é através da mídia, o papel da mídia e dos formadores de opinião é de transmitir para a população informações baseadas nas Regras de Tóquio e não de forma sensacionalista, só assim é possível melhorar o sistema punitivo no Brasil (CAPPI, 2002). 


\section{ATIVIDADE FÍSICA}

Sobre a atividade física a "Regras Mínimas para o Tratamento dos Reclusos" (Regra) determina que haja espaço, instalações e equipamentos adequados e no artigo 23 da Lei de Execução Penal (LEP - lei 7210/1984) é função do serviço de assistência social promover a recreação, mas foi relatado que em alguns lugares não há espaço para atividade física e os equipamentos são feitos de forma improvisada pelos presos, isso pode ser visto na fala de "Y": "lá também tinha atividade física, mas não em todas as cadeias, [...] não é toda cadeia que tinha quadra de futebol".

A prática de atividade física dependia exclusivamente dos presos, o Estado de vez em quando fornecia uma bola, para realizar atividade física "X" e " $Y$ " e os outros presos que estavam juntos dependiam da própria criatividade e da reciclagem de materiais, no relato de "Y" "com garrafa faziam peso e nós fazíamos tipo uma academia, e fazia uns exercícios de puxar e levantar peso", " $X$ " fala "aonde eu estava era mais futebol e muitas vezes era até [com] uma bola que nós mesmo improvisava de meia pra passar o tempo [...] a quadra era um cimentão bravo e os materiais tudo improvisado, pedaço de cabo de vassoura com as garrafas amarradas nas pontas, os peso era uns sacos [...] a luva [de boxe] era um pano velho, pedaço de lençol, cortina velha".

Os instrutores físicos eram presos nas mesmas condições que eles, instrutores que provavelmente tiveram uma base prática para estarem ali ensinando, sobre os instrutores "Y" falou que "sempre tem um lá, se entende eu não sei, ele demonstrava o que tinha pra fazer, fazer tantos de tal jeito [...] tipo um personal trainer [...] o cara tá preso também. Lá no sistema. [...] da parte do funcionário, nem futebol nós tinha”.

$\mathrm{Na}$ Regra tem que na falta de pessoal qualificado para observar as atividades físicas o médico torna-se o responsável, mas como foi visto há pessoal, porém não qualificado, que são os próprios presos.

A prática esportiva e a atividade física são ferramentas para reeducar o preso, porém o Estado abandonou essa ferramenta nas mãos do preso e seu uso agora é somente para passar o tempo, ganhar dinheiro em apostas ou disputar drogas como prêmio de acordo com "Y" e "X". Fazendo uma analogia com uma faca, sob os cuidados do Estado a faca é utilizada na cozinha para a preparação de alimentos, quando o preso toma essa ferramenta ela passa a ser utilizada para motins e assassinatos.

A prática esportiva e a atividade física por si só não agregam valores positivos, para isso é necessário alguém preparado para tal tarefa, para exemplificar foi constatado o aumento de conduta criminosa entre os atletas jovens ao ponto de ser criado nos EUA a National Coalition Against Violent Athletes (NCAVA 
- Coalizão Nacional Contra Atletas Violentos) formada por voluntários que investigam atletas violentos $\mathrm{e}$ ajudam as vítimas desses atletas (STAFFO, 2001).

Os índices de criminalidade envolvendo atletas são justificados pela tolerância e incentivo dos técnicos a comportamentos agressivos durante as competições (STAFFO, 2001).

Professores de EF e técnicos estão mais próximos dos atletas, portanto podem ser os primeiros a descobrir o atleta com tendência a agressividade prestando atenção na fala do atleta e se necessário encaminhá-lo para um psicólogo (STAFFO, 2001). Mas será que alguns treinadores estão dispostos a diminuir o rendimento da equipe para punir exemplarmente alguns atletas?

Para reduzir a criminalidade entre os atletas é preciso que os técnicos e professores de EF devam modificar a sua estratégia de orientar os jogadores, ensinar a ter comportamento social melhor e as escolas e faculdades devem avaliar o comportamento dos alunos, serem intolerante a violência e criar conselhos para avaliar e fiscalizar alunos (STAFFO, 2001).

Da forma como a prática esportiva e a atividade física estão organizados nas detenções ao invés de reeducar os presos, acaba refletindo os valores do ambiente em que esta, mas se o Estado ver a importância dessas ferramentas e utilizá-las adequadamente podem obter bons resultados.

Um exemplo é que no programa West Yorkshire Sports Counselling os alunos praticam 4 modalidades durante 12 semanas, reuniões ocorrem entre aquele que lidera a modalidade com os participantes para definir o programa. Uma autoridade local da modalidade é responsável em fornecer local e material para a prática. Após as 12 semanas o participante pode trabalhar na área esportiva (NICHOLS, 1999).

Ao comparar 23 participantes com 8 ou mais semanas no programa com 13 participantes com 7 ou menos semanas. Aqueles que fizeram 8 ou mais semanas foram menos reincidentes do que os outros condenados, enquanto que o outro grupo não houve diferença com os que não participaram do programa, assim o programa atinge seus objetivos. Mas não é apenas o programa o único responsável pelo sucesso, as pessoas que trabalham lá orientando os participantes têm a sua importância, pois chegam a formar laços de amizade com os detentos. A melhora da auto-imagem ocorrida no programa auxilia o ex-detento a manter bom comportamento e a conquistar emprego (NICHOLS, 1999). 
$\overline{\text { Um exemplo brasileiro é do Centro de Reabilitação de Crianças Infratoras de São Gonçalo, inicialmente }}$ ocorriam dificuldades em educar os infratores devido a resistência deles em participar das aulas e seguir regras, porém através do futebol que é a "paixão nacional", os instrutores conseguirão a participação e educar os menores, mesmo nas condições precárias fornecidas pelo Estado (SILVA; AMORIM, 2003).

Porém o Estado está longe de usar a prática esportiva e a atividade física para reabilitar o detento, o mais próximo que se chegou foi através do programa Pintando a Liberdade do Ministério do Esporte, apesar do esporte ser o pano de fundo, o que ocorre é a tentativa de ressocializar o preso fazendo com que ele trabalhe produzindo material esportivo para o programa Segundo Tempo que se destina ao esporte educacional de crianças e adolescentes em situação de risco social.

No caso de "Z" que passou os meses em uma D.P. ele relatou que não fez "atividade física nenhuma, só andar pra lá e pra cá pra esticar as pernas porque D.P. não tem espaço nem pra você andar direito. [...] [Sobre fazer exercício físico] nem eu e não vi ninguém fazendo atividade física como exercício, só fazer buraco e caminhada", ou seja, só tinha como atividade andar e fazer buraco, o que é obvio que isto aconteça já que não há atividade como válvula de escape para passar o tempo ou simplesmente para gastar energia.

\section{O RETORNO}

Com o ganho da liberdade, "X" e " $Z$ " não conseguiram empregos, para " $X$ " isso ocorre porque fica registrado que está na condicional. Para "Z" "arranjar serviço registrado é difícil sim, discriminação... patrão perde a confiança”.

Foi estipulado para "Y" fazer trabalho comunitário todos os domingos e ele faz de vez em quando e não é voltado para a ressocialização, pois, "você chega lá, dá um serviço pra você, dá uma vassoura, dá uma pá e te solta lá", ou seja, não há alguém orientando para que o trabalho tenha o efeito educador.

"Y" só conseguiu trabalho remunerado por causa da família, nas palavras dele "a família discriminou, mas por outro lado se não fosse a família eu estaria na rua [...] talvez desempregado e até fazendo uns corre [atividade criminosa] aí".

Devido as dificuldades " $\mathrm{X}$ " voltou a praticar crime. "depois disso [de estar preso] escalei mais duas fitas aí [cometi crime mais duas vezes], mas quase que eu arrumei mais cadeia de novo". "Y" mesmo com o auxilio da família depois de solto voltou por um tempo ao crime, pois como ele relatou, "cheguei a 
$\overline{\text { vender droga ainda, porque [...] antes já estive duas vezes preso no artigo 12, que é tráfico, [...] mas com }}$ o auxilio da minha esposa ela me tirou disso e não deixou eu vender droga, [...] só sou usuário".

Apesar da pesquisa conter apenas 3 entrevistados, é possível observar que quanto mais tempo esteve nas celas, maior foi a tendência para o crime após a liberdade, " $\mathrm{X}$ " ficou mais tempo preso e tentou assaltar 2 vezes depois que esteve preso, "Y" chegou a traficar por um tempo e "Z" não cometeu mais crime.

\section{CONCLUSÃO}

A prática esportiva e a atividade física são engrenagens que fazem parte de um maquinário para a recuperação do ex-detento onde todas as engrenagens estão comprometidas.

Dessa forma não adianta olhar apenas para a prática esportiva e a atividade física como uma forma de recuperar os presos, pois as outras engrenagens iriam reduzir a sua potencialidade travando o seu funcionamento, porém pode ser um "ponta pé inicial", pois diferente do trabalho e das aulas teóricas na escola, a aula de EF é prazerosa e assim facilitaria a educação de valores para os presos que freqüentariam as aulas mesmo que a sua participação não correspondam a redução da pena, pois eles fazem a prática esportiva e atividade física atualmente por motivação própria.

$\mathrm{Na}$ situação atual a prática esportiva e a atividade física são totalmente controlados pelos presos, sendo que os instrutores, que também são presos, apenas transmitem técnicas e preparação física baseada em conhecimento da prática, por essa razão não são transmitidos valores como fair play, autonomia, trabalho em grupo... o que aparenta é que o esporte reflete o ambiente a sua volta o que explicaria campeonatos onde o vencedor tem como prêmio drogas ilícitas para o todo time fugir da dura realidade.

\section{REFERÊNCIAS}

BERRA, J. A. P.; BACETTI, L B.; BUZO, A. A.. Soroprevalência de HIV, sífilis, hepatite B e C em mulheres do Centro de Ressocialização Feminino, Rio Claro, São Paulo. Revista Instituto Adolfo Lutz, v. 65 , n. 2, p. 133-136, 2006

BIBLIOTECA VIRTUAL DE DIREITOS HUMANOS DA UNIVERSIDADE DE SÃO PAULO, Direito dos Presos Detidos. Disponível em: $<$ http://www.direitoshumanos.usp.br/counter/Onu/Prisioneiros/Prisioneiros.html> Acesso em: 08 jan. 2008 . 
CAPPI, C. C. B. As regras de Tóquio e as medidas alternativas. Jus Navigandi, Teresina, v. 6, n. 58, ago. 2002.

DA FONSECA, K. P. (Re) Pensando o Crime como uma Relação de Antagonismo entre seus Autores e a Sociedade. Psicologia Ciência e Profissão, Brasília, v. 26, n. 4, p. 532-547, 2006.

DARIDO, S. C.; RANGEL-BETTI, I. C.; RAMOS, G. N. S.; GALVÃO, Z.; FERREIRA, L. A.; MOTA E SILVA, E. V.; RODRIGUES, L. H.; SANCHES NETO, .; PONTES, G.; CUNHA, F. A Educação Física, a Formação do Cidadão e os Parâmetros Curriculares Nacionais. Revista Paulista de Educação Física, São Paulo, v. 15, n. 1, p. 17-32, 2001.

DE CARVAlHO, T. M. P.. A Perspectiva Ressocializadora na Execução Penal Brasileira: o abandono do ideal ressocializador em direção a um direito penal do inimigo: Revista Eletrônica de Ciências Jurídicas, São Luís, n. 1, 2004.

DE SÁ, A. A.. A "Ressocialização" de Presos e a Terceirização de Presídios - Impressões Colhidas por um Psicólogo em Visita a Dois Presídios Terceirizados. Revista da Fundação Escola, Brasília, v. 21, n. 1, 2005.

DIÁRIO OFICIAL de 13/07/1984. Lei de Execução Penal (7.210/1984). Disponível em $<$ http://legislacao.planalto.gov.br/legisla/legislacao.nsf/fraWeb?OpenFrameSet\&Frame=frmWeb2\&Src= \%2Flegisla\%2Flegislacao.nsf\%2FViw_Identificacao\%2Flei\%25207.210-

1984\%3FOpenDocument\%26AutoFramed> Acesso em: 09 jan. 2008

GÓES, E.; M. R. L. As unidades prisionais do Oeste Paulista: implicações do aprisionamento e do fracasso da tentativa da sociedade de isolar por completo parte de si mesma. Terra Livre, São Paulo, v. 18, n. 19, p. 163-176, 2002.

GOMES, L. F. Teoria diferenciada de Schmidhäuser e o sistema penal brasileiro. Jus Navigandi, Teresina, v. 10, n. 1037, 2006

HARTMANN, D.; DEPRO, B. Rethinking Sports-Based Community Crime Prevention: A Preliminary Analysis of the Relationship Between Midnight Basketball and Urban Crime Rates. Journal of Sport \& Social Issues, Thousand Oaks, v. 30, n. 2, p. 180-196, 2006.

KORSAKAS, P.; DE ROSE JR, D. Os Encontros e Desencontros Entre Esporte e Educação: Uma Discussão Filosófico-Pedagógica. Revista Mackenzie de Educação Física e Esporte, São Paulo, v. 1, n. 1, p. 83-93. 2002.

MAIA, D. C. A Falta de Qualificação Profissional como um dos Fatores na Reincidência do Preso. 2003. 45 f. Monografia (lato sensu) - Universidade Federal do Paraná, 2003. 
MORRIS, L.; SALLYBANKS, J.; WILLIS, K.; M., Toni. Sport, physical activity and antisocial behaviour in youth. Australian Institute of Criminology Research and Public Policy Series, Canberra, $\mathrm{n}$. 49, 2003.

NICHOLS, G. Developing a Rationale for Sports Counselling Projects. The Howard Journal of Criminal Justice, Cambridge, v. 38, n. 2, p. 198 - 208, 1999.

PASTRE, M. A Educação Física na Busca da Excelência Humana e Acadêmica. 2001. 99 f. Dissertação (mestrado em engenharia de produção) - Engenharia de Produção, Universidade Federal de Santa Catarina, Florianópolis. 2001.

PEREIRA, M. P. A remição de pena à luz da ressocialização do condenado. Jus Navigandi, Teresina, v. 4, n. 45, 2000.

PINHEIRO, M .D. O cárcere e o "homicídio oficial". Jus Navigandi, Teresina, v. 2, n. 25, 1998.

PORTUGUES, M. R. Educação de adultos presos. Educação e Pesquisa, São Paulo, v. 9, n. 2, p. 355-374, 2001.

RICHARDSON, R. J. Entrevista. In: RICHARDSON, R. J. Pesquisa Social: Métodos e Técnicas. São Paulo: Atlas, 1989 p. 160-172.

RUBIO, K; CARVALHO, A L. Areté, fair play e o movimento olímpico contemporâneo. Revista Portuguesa de Ciências do Desporto, Porto, v. 5, n. 3, p. 350-357, 2005.

SEQUEIRA, V. C.. Porque o carcereiro não deixa as portas da prisão abertas?. Interações, São Paulo, v. 9, n. 18, p. 61-74, 2004.

SILVA, P. V. C.; AMORIM, Y. H. A. Menores Infratores Versus Educação Física: Expectativas, Reflexões, Conflitos e Possibilidades. In: Encontro Fluminense de Educação Física Escolar, VII. Universidade Federal Fluminense, Centro de Estudos Gerais, Departamento de Educação Física e Desportos, Programa de Pós-Graduação. Anais do VII Encontro Fluminense de Educação Física Escolar: VII EnFEFE - Dificuldades e Possibilidades da Educação Física Escolar no Atual Momento Histórico. Niterói/RJ, Agosto 2003. p. 181 - 183.

STAFFO, D. F. Strategies for Reducing Criminal Violence Among Athletes. Journal of Physical Education, Recreation \& Dance, Danvers, v. 72, n. 6, p. 39 - 42, 2001.

THOMAS, J. R.; NELSON, J. K. Pesquisa Qualitativa. IN: THOMAS, J. R.; NELSON, J. K. Métodos de pesquisa em atividade física. Porto Alegre: Artmed, 2002, p. 322-336.

VASCONCELOS, A. S. F. A Saúde sob Custódia: um estudo sobre Agentes de Segurança Penitenciária no Rio de Janeiro. 2000. 66 f. Dissertação (mestrado em ciências na área da saúde) - Escola Nacional de Saúde Pública, Fundação Oswaldo Cruz, Rio de Janeiro. 
Marco Ferretti

Escola de Educação Física e Esporte da Universidade de São Paulo

Jorge Dorfman Knijnik

School of Education - Bankstown Campus - University of Western Sydney

J.Knijnik@uws.edu.au

\section{Referencia do artigo:}

ABNT

FERRETTI, M.; KNIJNIK, J. D. A prática esportiva e atividade física podem educar pessoas atrás das grades?. Conexões, v. 7, n. 3, p. 59-73, 2009.

APA

Ferretti, M., \& KNIJNIK, J. D. (2009). A prática esportiva e atividade física podem educar pessoas atrás das grades?. Conexões, 7(3), 59-73.

\section{VANCOUVER}

Ferretti M, KNIJNIK JD. A prática esportiva e atividade física podem educar pessoas atrás das grades?. Conexões, 2009; 7(3): 59-73. 